\title{
Viral Hepatitis: Past and Future of HBV and HDV
}

\author{
Emmanuel Thomas, Masato Yoneda, and Eugene R. Schiff \\ Schiff Center for Liver Diseases, University of Miami Miller School of Medicine, Miami, Florida 33136 \\ Correspondence: eschiff@med.miami.edu
}

Viral hepatitis is a significant disease afflicting hundreds of millions of people. Hepatitiscausing viruses initiate significant morbidity and mortality by establishing both acute and chronic infections, and several of these viruses are specifically associated with the development of hepatocellular carcinoma (HCC). Consequently, intense research efforts are focused on increasing our understanding of virus biology and on improving antiviral therapy. Even though viral hepatitis can be caused by several viruses from a range of virus families, the discovery of components of the hepatitis B virus (HBV) became a catalyst for the development of diagnostic assays that differentiate between these viruses as well as strategies for novel methods of vaccine development. Improvements in both the treatment and prevention of viral hepatitis are advancing rapidly. However, HBV, along with the associated infection by the hepatitis $\mathrm{D}$ virus, is still among the most common pathogens afflicting humans.

$\mathrm{O}$ ver the past 50 years we have witnessed major advances in the study of the epidemiology, diagnosis, pathogenesis, natural history, treatment, and prevention of viral hepatitis. Viral hepatitis A, B, C, D, and E are well defined. There are safe and effective vaccines for hepatitis A and B, but not yet for hepatitis C. Hepatitis $\mathrm{E}$ vaccines have been developed more recently. Treatment for hepatitis B virus (HBV) infection is effective in rendering patients HBV DNA negative, stopping necroinflammation and often resulting in regression of fibrosis. Monumental achievements in the treatment of hepatitis $\mathrm{C}$ virus (HCV) infection have led to interferon (IFN)- and ribavirin-free curative oral therapy with combinations of direct antiviral agents, and we are quickly approaching short-term pangenotypic curative regimens.
In this review, we highlight the historical evolution of viral hepatitis, and this monograph specifically addresses the status of hepatitis B and D. Clearly, the challenge is to cure hepatitis $B$ with finite therapy that will eradicate covalently closed circular DNA (cccDNA) and eliminate the possibility of reactivation of viremia without persistence of hepatitis B. Thus, hepatitis D virus (HDV) infections will also resolve because HDV requires HBV envelope proteins for the production of infectious virus particles. However, even with the eradication of hepatitis $\mathrm{B}$ and $\mathrm{C}$ viremia, progression of cirrhosis in some and the risk for hepatocellular carcinoma (HCC) will haunt us for decades.

Throughout the world over the past century, viral hepatitis has emerged as a significant public health issue afflicting hundreds of millions of

Editors: Christoph Seeger and Stephen Locarnin

Additional Perspectives on Hepatitis B and Delta Viruses available at www.perspectivesinmedicine.org

Copyright (C) 2015 Cold Spring Harbor Laboratory Press; all rights reserved; doi: 10.1101/cshperspect.a021345

Cite this article as Cold Spring Harb Perspect Med 2015;5:a021345 
E. Thomas et al.

people. Hepatitis-causing viruses initiate significant morbidity and mortality by establishing both acute and chronic infections. In addition, several of these viruses are specifically associated with the development of HCC, which is one of the few cancers that is increasing in incidence. Furthermore, chronic infection frequently causes liver cirrhosis and hepatic decompensation, necessitating liver transplantation to ensure survival of the patient. Although the agents causing viral hepatitis are classified in diverse virus families, they all share the common ability to replicate in hepatocytes.

More than two billion people are estimated to have been infected by the HBV, and, of the total, there are $>300$ million HBV-infected individuals globally who are considered chronic carriers. Blood transfusion, sexual contact, and vertical transmission during childbirth are still the primary means of transmission of $\mathrm{HBV}$ among humans. Although successful vaccination strategies for HBV have been implemented throughout the world, new infections continue to occur. For HBV-infected patients, current therapy is very effective at achieving viral suppression; however, these medications can be very expensive and rarely lead to a durable cure. Consequently, intense research efforts are focused on increasing our understanding of virus biology and on improving antiviral therapy using novel therapeutic strategies to facilitate viral eradication.

Modern viral hepatitis research began in 1963 with the discovery of Australian antigen by Baruch Blumberg and Harvey Alter (Fig. 1). Although the transmission of viral hepatitis had been known to occur almost 100 years earlier through vaccination efforts and blood transfusions, this discovery initiated focused efforts to determine the molecular characteristics of agents causing viral hepatitis. Even though viral hepatitis can be caused by several viruses from a range of virus families, the discovery of components of the HBV became a catalyst for the de-

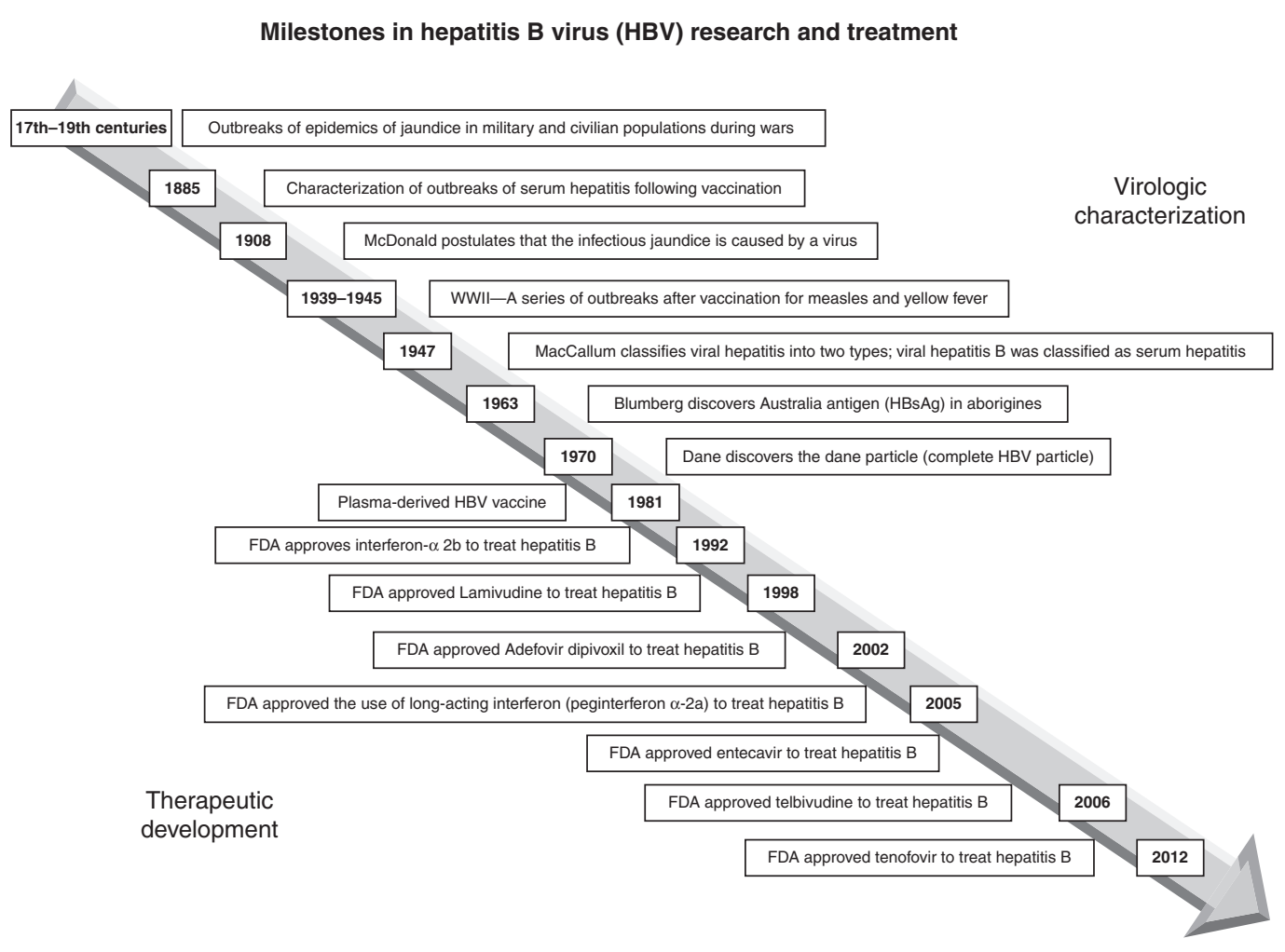

Figure 1. Timeline for milestones in HBV research and treatment. 
velopment of diagnostic assays that differentiate between these viruses as well as strategies for novel methods of vaccine development. In addition, early screening efforts for HBV greatly contributed to the largest decrease in blood transfusion-associated hepatitis to this date. Improvements in both the treatment and prevention of viral hepatitis are advancing rapidly; however, HBV, along with the associated infection with HDV, are still among the most common pathogens afflicting humans.

\section{HISTORY OF VIRAL HEPATITIS}

\section{Early Characterization}

Although precise insights into the molecular components of these viruses have been generated within the last half century, viral hepatitis, initially designated as "epidemic jaundice," was described in around 400 B.c. (Hippocrates). Several hundred years later, in the 8th century A.D., Pope Zacharias quarantined individuals with jaundice to prevent its spread throughout Rome, suggesting that the infectious nature of this clinical finding was apparent (Martin 2003). Interest in the basis of this disease increased in 1865, when Rudolf Virchow described a patient with symptoms of epidemic jaundice in whom the lower end of the common bile duct was blocked with a plug of mucus. This led to the term "catarrhal jaundice," because the disease was believed to be caused by catarrh as a result of mucus obstructing the bile duct. This caused confusion and limited progress in the understanding of the etiology behind epidemic jaundice (Gruber and Virchow 1865). Initially, the diagnosis of hepatitis required the existence of clinical features of hepatic injury and corresponding gross diagnosis if a liver biopsy was performed. In addition, evidence consistent with what was then known about the natural history of hepatitis was needed through the patient's history. For example, attempts at the etiologic diagnosis relied on estimates of incubation periods that required the patient to recall and recognize probable exposures that might serve as sources of infection. In many instances the responsible exposure was not identified, and, therefore, the time and manner of inoculation could not be determined. Even when a specific exposure was identified, overlapping incubation periods often resulted in misclassification of the disease (Feinstone et al. 1973).

Real insights into the transmissibility of viral hepatitis emerged in the 19th century as a result of epidemics of jaundice in military and civilian populations. A. Lurman published seminal work in 1885 showing that hundreds of individuals vaccinated to prevent smallpox subsequently became victims of jaundice. As described in this early publication (Lurman 1885), more than a thousand shipyard workers were initially vaccinated with lymph or interstitial fluid from previously exposed individuals because of a smallpox epidemic that occurred in Bremen in 1883. Several weeks later following vaccination, hundreds of the vaccinated shipyard workers fell ill and were diagnosed with jaundice. However, many other shipyard workers who were inoculated with lymph collected from different sources remained healthy. Although the etiologic agent was not discovered, the cause of this epidemic was carefully documented, providing proof that the lymph from contaminated sources or individuals was the predominant reason for the outbreak. These observations eventually gave rise to the term "serum hepatitis" (Findlay and MacCallum 1938), and in 1908, S. McDonald published his hypothesis that infectious jaundice was transmitted through viral infection (McDonald 1908).

During the early 20th century, research on viral hepatitis was largely descriptive, with only the causes of epidemics of jaundice being identified. After Lurman's work was published in 1885, many other epidemics were subsequently reported. Most of these occurred after 1909 with the introduction of the hypodermic needle. These were initially widely used and reused for administration of treatment for syphilis or trypanosomiasis. Interestingly, between 1939 and 1945 during World War II, a series of outbreaks of jaundice were reported after vaccination for measles and yellow fever. One of the largest of these outbreaks occurred in 1942, with $\sim 50,000$ episodes of jaundice reported among soldiers in the U.S. Army following administration of a 
yellow fever vaccine that contained human serum (Seeff et al. 1987; Martin 2003).

At the time of the Second World War, infections of the liver were believed to be caused by several distinct viruses, and this led to use of the term "viral hepatitis." Concomitantly, the use of aspiration needle biopsy in the liver for histologic characterization showed that epidemic jaundice was an inflammatory process and not an obstructive phenomenon as described by Virchow (Anonymous 1943; Sherlock 1984). In 1947, after almost 10 years of inquiry into the nature of this illness, F.O. MacCallum, a British hepatologist, classified viral hepatitis into two subtypes, namely, hepatitis A and hepatitis B (MacCallum 1947). Within this nomenclature, hepatitis A was designated as "infectious or epidemic" hepatitis and hepatitis B was designated as "serum" hepatitis to correspond with their observed routes of transmission. Even before the isolation of the causative viral agents, data from several epidemiologic studies showed that hepatitis A was mostly spread through the fecaloral route, whereas hepatitis B transmission took place parenterally. Subsequently, the World Health Organization (WHO) adopted these viral hepatitis terminologies.

Following the outbreaks that occurred in the 1940s, it became apparent that focused studies in humans would lead to significant advancement in the understanding of epidemic jaundice. Trials were conducted with incarcerated and mentally handicapped individuals using experimental methods that included directly administering contaminated material through several different routes of administration (Melnick and Boggs 1972). Saul Krugman conducted studies at the Willowbrook State School in New York that further distinguished the two types of hepatitis. The first, designated as MS1, was characterized by a shorter period of elevated liver enzymes and incubation of $\sim 40$ days that was extremely contagious and resembled infectious hepatitis. The second, designated as MS2, was characterized by longer periods of transaminitis and incubation and was less contagious. Patients infected with MS1 were subsequently immune to further infection with MS1 but not from infection with MS2. Furthermore, patients infected with MS2 material were not immune to infection with MS1 material. These studies confirmed that there were two main routes of spread most probably by two different pathogens, as indicated by the nomenclature previously mentioned (Krugman et al. 1967).

\section{Discovery of the Australian Antigen}

The early 1960s marked several important milestones in the history of viral hepatitis, catapulted by the discovery of the HBV surface antigen by Blumberg and Alter. Although it was a peculiar and serendipitous discovery, Blumberg's previous exploits had enabled the initial experiments to be conducted. In the 1950s, he collected blood samples from several indigenous populations located throughout the world. His goal was to study the inherited diversity in humans with a focus on finding the basis behind variability in disease susceptibility and outcomes. After these initial blood collection efforts, Blumberg assumed a position at the National Institutes of Health (NIH), where at the same time Alter was studying patients who had undergone a blood transfusion and subsequently developed febrile transfusion reactions. Using agar gel double diffusion, also known as Ouchterlony, Alter began testing serum from patients who had received multiple transfusions against serum that Blumberg had collected from individuals during his travels (Gerlich 2013). Initial efforts were focused on identifying new serum lipoproteins because Blumberg had already established that lipoproteins were polymorphic between individuals (Blumberg and Riddell 1963; Alter 2014).

The single most important event in hepatitis discovery and prevention was made in 1963 with the crude identification of the HBV surface antigen specifically through an Ouctherlony reaction between serum from an Australian aborigine and a hemophiliac patient (Blumberg et al. 1965). However, it was an unexpected finding because this initial precipitate did not take up a lipid stain that usually marked their previous Ouchterlony reactions. Surprisingly, a protein counterstain effectively marked the precipitate (Alter 2014). The identified protein, 
subsequently designated the Australian antigen (AuAg), was found to be present at high frequency in leukemia patients and in children with Down's syndrome, initially masking its true association with an agent of viral hepatitis that was a hypothesis at the time. (Blumberg et al. 1967). By 1967, accumulating evidence showed a strong correlation between the presence of $\mathrm{AuAg}$ and viral hepatitis, and this hypothesis was bolstered when a technician in Blumberg's laboratory developed hepatitis and was later found to be positive for the AuAg. In 1968, Prince, Murakami, and Okochi, through independent studies that built on the work of Krugman's characterization of MS1 and MS2, confirmed that AuAg was found specifically in patients who had serum hepatitis (Okochi and Murakami 1968; Prince 1968).

\section{Development of Tools to Screen for Viral Hepatitis}

With the confirmed association between viral hepatitis and the presence of the AuAg, Blumberg and Alter, along with others at the NIH, engaged in the development of screening and diagnostic tests to prevent hepatitis following blood transfusions. Initially, Ouchterlony was found to be fairly sensitive and specific, and it was subsequently used as a crude screening tool that became the first-generation test for viral hepatitis screening. This was rapidly followed by more sophisticated tests, such as radioimmunoassay that were more objective and quantitative measurement methods as opposed to using Ouchterlony, which was somewhat subjective (Gerlich 2013). These initial screening efforts contributed to the greatest decrease in incidence of transfusion-associated hepatitis, from $30 \%$ to $\sim 10 \%$ during the 1970s (Alter 2014).

\section{Discovery that AuAg Was the HBsAg}

During the early 1970s it was unclear exactly what AuAg was. At that time Blumberg and his team conducted studies examining purified AuAg using electron microscopy (EM). Using this technique they identified small round particles of variable size that, importantly, did not contain any nucleic acid. The fact that the AuAg was free of nucleic acid was also confirmed using other complementary techniques (Gerlich 2013). Concurrently, David S. Dane in 1970 used EM to inspect AuAg immune complexes as opposed to purified AuAg. In addition to the small particles observed by Blumberg's group, he also visualized larger particles similar in size to other viruses with a clearly visible inner core. Biochemical studies on the "Dane" particle revealed that this inner core was the nucleocapsid (HBV core antigen) and the outer surface protein was the AuAg, which was then designated as the HBV surface antigen (HBsAg) (Dane et al. 1970). The DNA genome of HBV was also identified during the same period, with DNA polymerase activity being discovered first in preparations of purified AuAg. Subsequently, the actual DNA genome was crudely identified as a product of this DNA polymerase activity. The presence of this endogenous DNA confirmed that the Dane particles contained intact HBV virus with its nucleic acid genome (Hirschman et al. 1971; Kaplan et al. 1973). After some time the HBV genome was ultimately cloned from the nucleic acid contained in the Dane particle (Robinson et al. 1974), and this cloned DNAwas injected into the livers of chimpanzees, resulting in acute HBV infection and further providing strong evidence that the Dane particles contained infectious HBV (Will et al. 1982).

\section{Vaccine Development with $\mathrm{HBsAg}$ and Antiviral Therapy}

Discovery of HBsAg in humans was also the predominant driver in the development of the first vaccine for viral hepatitis by specifically targeting HBV. A highly purified and inactivated vaccine was made targeting this viral protein using concentrated HBsAg from healthy human hepatitis B carrier plasma donors. At the time, this method was an unprecedented means of making a vaccine and required additional steps during the vaccine preparation stages using treatment with formalin, urea, and pepsin to inactivate any copurified pathogens (Hilleman et al. 1975). Initially, the vaccine was tested exhaustively for safety in primates, and these experiments showed that it was highly potent 
and induced neutralizing antibody. Specifically, in controlled studies performed in the mid1970s, chimpanzees given three doses of vaccine were protected against challenge using highly infectious doses of live human HBV given intravenously (Buynak et al. 1976). Subsequent studies in humans showed that the vaccine was highly protective and safe (McLean et al. 1983). Because HBV has been clearly shown to be an agent that promotes the development of HCC, the $\mathrm{HBV}$ vaccine is also considered by many to be the first effective cancer vaccine. Because of the efficacy and worldwide use of this vaccine, some believe that, through his work that led to the $\mathrm{HBV}$ vaccine, Blumberg ultimately prevented more cancer deaths than any person who has ever lived. As a result of his scientific achievements with HBV, Blumberg was awarded the Nobel Prize in Physiology or Medicine in 1976. That same year one of the first reports of possible therapy for HBV was published, with promising results observed in four patients treated with IFN (Greenberg et al. 1976). After additional studies were performed in larger cohorts, IFN $\alpha-2 b$ received U.S. Food and Drug Administration (FDA) approval as treatment for HBV in 1981. It took many more years until the next antiviral agent, lamivudine, received FDA approval in 1998. Additional antiviral agents have received FDA approval since then (Fig. 1), but progress has been slow in this area compared with $\mathrm{HBV}$ vaccine development, which advanced rapidly.

\section{Discovery of HDV and Other Viral Hepatidities}

Following the discovery of components of the HBV virion, efforts increased to identify other viral pathogens that cause viral hepatitis, and these subsequent discoveries aided in the eventual identification of HDV. The hepatitis Avirus (HAV) was discovered in 1973, using immune $\mathrm{EM}$, as was similarly performed previously for visualization of HBV. Preceding epidemiologic and direct human experimentation showed that HAV was transmissible by oral inoculation with filtered stool extracts from infected patients. Using this information, Feinstone, Kapikian, and Purcell discovered HAV in fecal samples obtained from human volunteers with appropriate clinical histories for hepatitis A (Feinstone et al. 1973). Specifically, stool specimens from these patients were incubated with convalescent serum from other distinct patients with hepatitis A, leading to the visualization of virus particles heavily coated with serum antibody. With the discovery of both HAV and HBV, research on viral hepatitis progressed, permitting isolation of more elusive viral pathogens with less distinctive clinical phenotypes.

During the late 1970s, the localization of HBV in the liver by immunostaining with antibodies targeting specific viral proteins was a routine diagnostic procedure. Variations in immunostaining of liver samples subsequently led to the recognition of a new protein complex, designated as the "delta" antigen and antibody in HBsAg-positive patients with chronic hepatitis. Specifically, staining for HBV proteins in a minority of patients resulted in a peculiar nuclear fluorescence pattern that was distinct from the typical nuclear fluorescence usually found in patients with chronic HBV infection (Rizzetto et al. 1977; Rizzetto 2015). Interestingly, when this particular patient subgroup was evaluated clinically, it was observed that they typically presented with more severe liver disease. Studies were then performed in chimpanzees previously unexposed to HBV but susceptible to infection and in animals with a high titer of anti-HBsAg that were immune to HBV. Chimpanzees in each of these groups were inoculated with the HBsAg-positive serum containing delta antigen, and surprisingly, no delta antigen expression was found in uninfected animals or in those immune to HBV. However, when further transmission studies were performed in chimpanzees that were already chronic carriers of the HBV, inoculation of these animals led to the appearance of large quantities of intrahepatic delta antigen. Further investigation led to the aforementioned discovery of the delta antigen, which was distinct from the known $\mathrm{HBV}$ proteins yet present only in HBsAg carriers. Additional experimentation showed that the delta antigen was a protein component of a defective RNAvirus requiring $\mathrm{HBV}$ for its own 
infection (Smedile and Rizzetto 2011), with its entire genome being cloned and sequenced in 1982 (Wang et al. 1986).

Interestingly, testing of samples stored at the $\mathrm{NIH}$ from patients with viral hepatitis revealed that HAV and HBV, and correspondingly HDV, were responsible for a minority of cases of viral hepatitis and, consequently, that other agents of viral hepatitis were also involved. Accordingly, a new term for another etiologic agent of viral hepatitis was coined as "non-A, non-B hepatitis” (NANBH) (Feinstone et al. 1975). Although it was believed that this agent would quickly be found (Alter 2014), it took more than a decade to discover the etiologic agent designated as HCV. In 1988, using a cDNA expression library constructed from pelleted nucleic acid from the serum of a chimpanzee with a high level of NANBH infection, Michael Houghton and colleagues reported the discovery of this virus (Choo et al. 1989), which was also validated using patient material from the NIH (Alter et al. 1989). A decade later, Houghton and Alter were awarded the Lasker Award in 2000 for the discovery of HCV. In 1990, only 1 year after the discovery of $\mathrm{HCV}$, an enterically spread form of NANBH was identified (Reyes et al. 1990) and designated as the hepatitis E virus (HEV) (Bradley 1990). HEV proved to be responsible for epidemics of hepatitis that occurred in Kashmir Valley in 1978, which involved an estimated 52,000 cases with 1700 deaths (Khuroo 1980). HEV continues to be a significant cause of hepatitis throughout the world and may be responsible for additional morbidity and mortality, including establishing chronic viral hepatitis that is currently underappreciated by the healthcare community (Sclair and Schiff 2013).

\section{CLINICAL MANIFESTATIONS AND PATHOGENESIS OF VIRAL HEPATITIS}

Clinical manifestations of acute infection from agents causing viral hepatitis vary from asymptomatic or mild flulike illness without jaundice to fatal liver failure, depending on the patient's immune response, the viral pathogen involved, and other unknown virus-host factors. Acute viral hepatitis can be characterized by a prodro- mal phase of profound anorexia, nausea, vomiting, malaise, and fever. In addition, urticaria and arthralgia occur occasionally. Subsequently, the icteric phase may begin and jaundice, if present, usually peaks in 1-2 weeks and fades during a 2- to 4-week recovery phase. Acute liver failure (ALF), a rare syndrome characterized by rapid clinical deterioration with the onset of hepatic encephalopathy and coma without known preexisting liver disease, may develop in some patients (Hoofnagle et al. 1995; Lee et al. 2008). ALF, also designated as fulminant hepatitis, carries a high morbidity and mortality. With regards to acute viral hepatitis, as with many other etiologies of ALF, care is mainly supportive. Lamivudine may be considered for treatment of patients with acute HBV, although evidence of efficacy is questionable (Mindikoglu et al. 2006; Lok and McMahon 2009; Zoulim and Durantel 2015).

The clinical features of chronic viral hepatitis vary widely and reflect the dynamic interaction between the various viral pathogens and the patient's innate and adaptive antiviral immune responses. In some individuals chronic hepatitis will remain asymptomatic for years, whereas others can experience alternating periods of asymptomatic infection interrupted by symptomatic flares of active hepatitis. Other patients can experience rapid progression of chronic hepatitis to cirrhosis and, finally, HCC. Characteristic signs and symptoms of chronic liver disease include nonspecific malaise, anorexia, fatigue, low-grade fever, and nondescript right upper quadrant abdominal discomfort. Clinical presentation that includes jaundice seldom occurs, and it is often absent. About $90 \%$ of the patients with acute HBV infection experience complete recovery and subsequently develop persistent immunity. HBV may also persist at very low levels for extended periods and is designated "occult HBV infection." Evidence for the existence of this clinical state was obtained when $\mathrm{HBV}$ reactivation occurred during periods of severe immunosuppression, such as in patients undergoing chemotherapy for treatment of a malignancy.

The risk of developing chronic HBV infection decreases with age at the time of initial 
infection. Neonates, because of their weaker immune system, have a $90 \%$ chance of developing chronic HBV infection, compared with a $30 \%$ chance for children aged $1-5$ years and a $5 \%$ chance for adults (Villeneuve 2005). Chronic carriers of HBV are at increased risk of developing cirrhosis, hepatic decompensation, and HCC (Beasley 1988). The annual incidence of HCC in hepatitis B carriers is $\sim 0.5 \%$ (Beasley et al. 1981). This annual incidence increased with age, so that by age 70 , the incidence can be as high as $1 \%$. The incidence in patients with known cirrhosis further increases to $2.5 \%$ per year (Bruix and Llovet 2010).

In the setting of HBV infection, coinfection or superinfection with HDV usually results in more severe liver disease (Smedile et al. 1981). In the patient who is coinfected with $\mathrm{HBV}$ and HDV (i.e., both viruses were acquired at the same time), the clinical symptoms are usually moderate, but they can be severe with acute fulminant hepatitis. In addition, fulminant hepatitis with coinfection is more likely than with HBV monoinfection. Chronic coinfection with both HBV and HDV occurs in $<5 \%$ of patients.

Individuals with previous chronic $\mathrm{HBV}$ monoinfection are also vulnerable to superinfection with HDV after exposure to blood from an individual infected with both HBV and HDV. This may be observed as an acute flare of hepatitis, and this flare can lead to the initial discovery of the preexisting HBV infection. Superinfection with HDV can be self-limited and result in clearance of both viruses, although this outcome is rare. Most patients with superinfection develop a progressive form of chronic hepatitis, and it often manifests as a worsening clinical illness in a previously stable chronic carrier of HBV. Clinical illness with superinfection can be rapidly progressive, leading to cirrhosis within 2 years in $10 \%-15 \%$ of patients (Rizzetto 2010).

Apart from causing morbidity and mortality directly through liver disease, viral hepatitis is associated with a spectrum of extrahepatic manifestations that can be clinically significant. Symptoms from these clinical sequelae can frequently arise in patients with chronic viral hepatitis; however, many infected patients may nev- er experience them and they can precede or follow the development of overt liver disease (Amarapurkar and Amarapurkar 2002). Extrahepatic manifestations can occur in multiple organs including the kidneys, eyes, joints, skin, and immune and nervous systems and can result in endocrine abnormalities, such as diabetes. Specifically, infection with $\mathrm{HBV}$ has been well recognized for causing a variety of manifestations that include skin rash, arthritis, arthralgia, glomerulonephritis, polyarteritis nodosa, and papular acrodermatitis (Han 2004). HCV infection has also been associated with cryoglobulinemia, glomerulonephritis, high titer of autoantibodies, idiopathic thrombocytopenic purpura, lichen planus, Mooren's corneal ulcer, Sjögren's syndrome, porphyria cutanea tarda, and necrotizing cutaneous vasculitis (Pyrsopoulos and Reddy 2001). Some of these conditions are commonly found, whereas others are an infrequent occurrence. The precise pathogenesis of these extrahepatic complications has not been fully characterized, although the majority of them arise as a result of autoimmune phenomena or are a result of chronic immune activation resulting in immune complex reactions that affect multiple organs (Vassilopoulos and Calabrese 2005).

\section{AREAS OF FUTURE INVESTIGATION}

The study of the mechanisms underlying how hepatitis viruses manifest as chronic infection is an area of intense research. In addition, the molecular pathways that are affected by chronic infection and that facilitate the development of HCC remain to be fully characterized. Current experimental evidence implicates the detection of viral nucleic acid in the infected cell as one of the first events that allow the recognition that a viral infection has taken place (Kumar et al. 2009). Activation of downstream signaling pathways to initiate an innate antiviral response then takes place as infected hepatocytes try to thwart viral persistence and subvert subsequent spread of infection. These intrinsic innate antiviral pathways are usually very effective at clearing viral infections because only a handful of viral pathogens are able to elicit chronic disease 
in humans (Gale and Sen 2009). Precise insights pertaining to the mechanisms by which HBV and HDV are able to specifically subvert these antiviral responses and establish chronic infection are needed. In addition, the means by which the genomes of these viruses persist intracellularly are still not well understood.

With regard to $\mathrm{HBV}$, chronic infection is established by an intracellular replicative form of the viral genome designated as cccDNA. During infection, cccDNA persists in the nucleus of the cell as a stable episome and acts as a template for the transcription of viral genes (Locarnini and Zoulim 2010). Because of the long halflife of hepatocytes in the liver, a limiting factor in curing infection is believed to be the clearance of intracellular cccDNA from infected cells (Zoulim 2004). Therefore, studies to foster the eradication of cccDNA from infected cells are currently under way (Lucifora et al. 2014). However, in the clinical setting, the most difficult aspect of the inquiry into HBV cccDNA includes the requirement for liver tissue as well as the lack of sensitive, specific, and quantitative methods to detect cccDNA from biopsies. In addition, the dearth of robust laboratory models that accurately recapitulate in vivo HBV infection have hampered the study of cccDNA persistence and removal (Dandri et al. 2013).

Although a relatively rare event, complete clearance of cccDNA does occur in vivo. Several immune mechanisms have been proposed to mediate intracellular cccDNA clearance. First, a cytolytic mechanism has been demonstrated by which infected cells are killed by cytotoxic $\mathrm{T}$ lymphocytes and replaced by uninfected hepatocytes. A second, noncytolytic, cytokine-induced removal of cccDNA directly through activation of intracellular antiviral pathways has also been proposed. There is supporting evidence from animal models suggesting that these mechanisms are involved and that, ultimately, a multipronged immune response is required to resolve chronic infection in patients (Bertoletti and Ferrari 2012). However, the direct, cytokinemediated mechanism suggests that cccDNA may be susceptible to noncytolytic clearance by antiviral cytokines, specifically, clearance not requiring death of the infected cell. Although the cytotoxic T-cell response has been relatively well characterized, research is needed to increase our understanding of the initial antiviral responses that can lead to the production of antiviral cytokines from the infected cell that may lead to the clearance of cccDNA and exactly how this response specifically targets the viral genome (Bauer et al. 2011; Lucifora et al. 2014).

\section{CONCLUSION}

It has taken several centuries to identify the causes of the epidemic jaundice that increased after early attempts to initiate public vaccination programs and with the widespread application of blood transfusions from unrelated donors. Subsequently, many decades were needed to discover the pathogens that are the etiologic agents behind these infectious diseases. In contrast, the medical and research communities have rapidly developed effective strategies to thwart most of these pathogens. Specifically, development of highly effective $\mathrm{HBV}$ vaccines as a preventive measure against new infections has resulted in a decrease in both the prevalence and spread of HBV and its associated pathogen, HDV. However, chronic HBV infection still necessitates improvement in therapeutic intervention to allow for successful eradication of this virus, as has recently been achieved for HCV infection. In addition, even with cure, chronically infected patients still are at increased risk of developing HCC, which remains one of the deadliest forms of cancer because it is relatively resistant to most forms of chemotherapy. Therefore, additional efforts are necessary to further our understanding of the mechanisms by which these viruses manifest as chronic infection and the molecular pathways that are ultimately involved in the development of liver disease and HCC.

\section{REFERENCES}

${ }^{*}$ Reference is also in this collection.

Alter HJ. 2014. The road not taken or how I learned to love the liver: A personal perspective on hepatitis history. Hepatology 59: 4-12. 
E. Thomas et al.

Alter HJ, Purcell RH, Shih JW, Melpolder JC, Houghton M, Choo QL, Kuo G. 1989. Detection of antibody to hepatitis $C$ virus in prospectively followed transfusion recipients with acute and chronic non-A, non-B hepatitis. New Engl J Med 321: 1494-1500.

Amarapurkar DN, Amarapurkar AD. 2002. Extrahepatic manifestations of viral hepatitis. Ann Hepatol 1: 192 195.

Anonymous. 1943. Epidemic infective hepatitis. $\mathrm{Br} \mathrm{Med} J$ 2: $680-681$.

Bauer T, Sprinzl M, Protzer U. 2011. Immune control of hepatitis B virus. Dig Dis 29: 423-433.

Beasley RP. 1988. Hepatitis B virus. The major etiology of hepatocellular carcinoma. Cancer 61: 1942-1956.

Beasley RP, Hwang LY, Lin CC, Chien CS. 1981. Hepatocellular carcinoma and hepatitis B virus. A prospective study of 22,707 men in Taiwan. Lancet 2: 1129-1133.

Bertoletti A, Ferrari C. 2012. Innate and adaptive immune responses in chronic hepatitis $\mathrm{B}$ virus infections: Towards restoration of immune control of viral infection. Gut 61: 1754-1764.

Blumberg BS, Riddell NM. 1963. Inherited antigenic differences in human serum $\beta$ lipoproteins. A second antiserum. J Clin Invest 42: 867-875.

Blumberg BS, Alter HJ, Visnich S. 1965. A "new” antigen in leukemia sera. JAMA 191: 541-546.

Blumberg BS, Gerstley BJ, Hungerford DA, London WT, Sutnick AI. 1967. A serum antigen (Australia antigen) in Down's syndrome, leukemia, and hepatitis. Ann Intern Med 66: 924-931.

Bradley DW. 1990. Hepatitis non-A, non-B viruses become identified as hepatitis C and E viruses. Prog Med Virol 37: 101-135.

Bruix J, Llovet JM. 2010. Two decades of advances in hepatocellular carcinoma research. Semin Liver Dis 30: 1-2.

Buynak EB, Roehm RR, Tytell AA, Bertland AU II, Lampson GP, Hilleman MR. 1976. Development and chimpanzee testing of a vaccine against human hepatitis B. Proc Soc Exp Biol Med 151: 694-700.

Choo QL, Kuo G, Weiner AJ, Overby LR, Bradley DW, Houghton M. 1989. Isolation of a cDNA clone derived from a blood-borne non-A, non-B viral hepatitis genome. Science 244: 359-362.

Dandri M, Lutgehetmann M, Petersen J. 2013. Experimental models and therapeutic approaches for HBV. Semin Immunopathol 35: 7-21.

Dane DS, Cameron CH, Briggs M. 1970. Virus-like particles in serum of patients with Australia-antigen-associated hepatitis. Lancet 1: 695-698.

Feinstone SM, Kapikian AZ, Purcell RH. 1973. Hepatitis A: Detection by immune electron microscopy of a viruslike antigen associated with acute illness. Science 182: $1026-$ 1028.

Feinstone SM, Kapikian AZ, Purcell RH, Alter HJ, Holland PV. 1975. Transfusion-associated hepatitis not due to viral hepatitis type A or B. New Engl J Med 292: 767-770.

Findlay GM, MacCallum FO. 1938. Hepatitis and jaundice associated with immunization against certain virus diseases. Proc R Soc Med 31: 799-806.
Gale M Jr, Sen GC. 2009. Viral evasion of the interferon system. J Interferon Cytokine Res 29: 475-476.

Gerlich WH. 2013. Medical virology of hepatitis B: How it began and where we are now. Virol J 10: 239.

Greenberg HB, Pollard RB, Lutwick LI, Gregory PB, Robinson WS, Merigan TC. 1976. Effect of human leukocyte interferon on hepatitis B virus infection in patients with chronic active hepatitis. New Engl J Med 295: 517-522.

Gruber W, Virchow R. 1865. Uber das vorkommen und den nachweiss des hepatogenen, insbesondere des kattarrhalischen icterus [Occurrence and diagnosis of the hepatic, and in particular, the catarrhal icterus]. Virchows Arch 32: $117-125$.

Han SH. 2004. Extrahepatic manifestations of chronic hepatitis B. Clin Liver Dis 8: 403-418.

Hilleman MR, Buynak EB, Roehm RR, Tytell AA, Bertland AU, Lampson GP. 1975. Purified and inactivated human hepatitis B vaccine: Progress report. Am J Med Sci 270: 401-404.

Hippocrates. De morbus internis. In Oeuvres complètes (1844), Vol. 7, pp. 237-243. Chez H. Ballière, London.

Hirschman SZ, Vernace SJ, Schaffner F. 1971. DNA polymerase in preparations containing Australia antigen. Lancet 1: 1099-1103.

Hoofnagle JH, Carithers RL Jr, Shapiro C, Ascher N. 1995. Fulminant hepatic failure: Summary of a workshop. Hepatology 21: 240-252.

Kaplan PM, Greenman RL, Gerin JL, Purcell RH, Robinson WS. 1973. DNA polymerase associated with human hepatitis B antigen. J Virol 12: 995-1005.

Khuroo MS. 1980. Study of an epidemic of non-A, non-B hepatitis. Possibility of another human hepatitis virus distinct from post-transfusion non-A, non-B type. Am J Med 68: 818-824.

Krugman S, Giles JP, Hammond J. 1967. Infectious hepatitis. Evidence for two distinctive clinical, epidemiological, and immunological types of infection. JAMA 200: 365-373.

Kumar H, Kawai T, Akira S. 2009. Pathogen recognition in the innate immune response. Biochem J 420: 1-16.

Lee WM, Squires RH Jr, Nyberg SL, Doo E, Hoofnagle JH. 2008. Acute liver failure: Summary of a workshop. Hepatology 47: 1401-1415.

Locarnini S, Zoulim F. 2010. Molecular genetics of HBV infection. Antivir Ther 15: 3-14.

Lok AS, McMahon BJ. 2009. Chronic hepatitis B: Update 2009. Hepatology 50: 661-662.

Lucifora J, Xia Y, Reisinger F, Zhang K, Stadler D, Cheng X, Sprinzl MF, Koppensteiner H, Makowska Z, Volz T, et al 2014. Specific and nonhepatotoxic degradation of nuclear hepatitis B virus cccDNA. Science 343: 1221-1228.

Lurman A. 1885. Eine icterus epidemic. Berl Klin Woschenschr 22: 20-23.

MacCallum FO. 1947. Homologous serum jaundice [An icterus epidemic]. Lancet 2: 691-692.

Martin NA. 2003. The discovery of viral hepatitis: A military perspective. J R Army Med Corps 149: 121-124.

McDonald S. 1908. Acute yellow atrophy. Edinb Med J 15: 208. 
Viral Hepatitis: Past and Future of HBV and HDV

McLean AA, Hilleman MR, McAleer WJ, Buynak EB. 1983. Summary of worldwide clinical experience with H-B-Vax (B, MSD). J Infect 7: 95-104.

Melnick JL, Boggs JD. 1972. Human volunteer and tissue culture studies of viral hepatitis. Can Med Assoc J 106: 461-467.

Mindikoglu AL, Regev A, Schiff ER. 2006. Hepatitis B virus reactivation after cytotoxic chemotherapy: The disease and its prevention. Clin Gastroenterol Hepatol 4: 10761081.

Okochi K, Murakami S. 1968. Observations on Australia antigen in Japanese. Vox Sang 15: 374-385.

Prince AM. 1968. An antigen detected in the blood during the incubation period of serum hepatitis. Proc Natl Acad Sci 60: 814-821.

Pyrsopoulos NT, Reddy KR. 2001. Extrahepatic manifestations of chronic viral hepatitis. Curr Gastroenterol Rep 3: $71-78$.

Reyes GR, Purdy MA, Kim JP, Luk KC, Young LM, Fry KE, Bradley DW. 1990. Isolation of a cDNA from the virus responsible for enterically transmitted non-A, non-B hepatitis. Science 247: 1335-1339.

Rizzetto M. 2010. Hepatitis D: Clinical features and therapy. Dig Dis 28: 139-143.

* Rizzetto M. 2015. HDV: Introduction and epidemiology. Cold Spring Harb Perspect Med doi: 10.1101/cshper spect.a021576.

Rizzetto M, Canese MG, Arico S, Crivelli O, Trepo C, Bonino F, Verme G. 1977. Immunofluorescence detection of new antigen-antibody system $(\delta /$ anti- $\delta$ ) associated to hepatitis B virus in liver and in serum of HBsAg carriers. Gut 18: 997-1003.

Robinson WS, Clayton DA, Greenman RL. 1974. DNA of a human hepatitis B virus candidate. J Virol 14: 384-391.
Sclair SN, Schiff ER. 2013. An update on the hepatitis E virus. Curr Gastroenterol Rep 15: 304.

Seeff LB, Beebe GW, Hoofnagle JH, Norman JE, BuskellBales Z, Waggoner JG, Kaplowitz N, Koff RS, Petrini JL Jr, Schiff ER, et al. 1987. A serologic follow-up of the 1942 epidemic of post-vaccination hepatitis in the United States Army. New Engl J Med 316: 965-970.

Sherlock S. 1984. Landmark perspective: Landmarks in viral hepatitis. JAMA 252: 402-406.

Smedile A, Rizzetto M. 2011. HDV: Thirty years later. Dig Liver Dis 43: S15-S18.

Smedile A, Dentico P, Zanetti A, Sagnelli E, Nordenfelt E, Actis GC, Rizzetto M. 1981. Infection with the delta agent in chronic HBsAg carriers. Gastroenterology 81: 992-997.

Vassilopoulos D, Calabrese LH. 2005. Extrahepatic immunological complications of hepatitis $\mathrm{C}$ virus infection. AIDS 19: S123-S127.

Villeneuve JP. 2005. The natural history of chronic hepatitis B virus infection. J Clin Virol 34: S139-S142.

Wang KS, Choo QL, Weiner AJ, Ou JH, Najarian RC, Thayer RM, Mullenbach GT, Denniston KJ, Gerin JL, Houghton M. 1986. Structure, sequence and expression of the hepatitis delta $(\delta)$ viral genome. Nature 323: 508-514.

Will H, Cattaneo R, Koch HG, Darai G, Schaller H, Schellekens H, van Eerd PM, Deinhardt F. 1982. Cloned HBV DNA causes hepatitis in chimpanzees. Nature 299: 740742.

Zoulim F. 2004. Antiviral therapy of chronic hepatitis B: Can we clear the virus and prevent drug resistance? Antivir Chem Chemother 15: 299-305.

* Zoulim F, Durantel D. 2015. Antiviral therapies and prospects for a cure of chronic hepatitis B. Cold Spring Harb Perspect Med doi: 10.1101/cshperspect.a021501. 


\section{$\&_{\mathrm{CSH}}^{\infty} \&$ Cold Spring Harbor

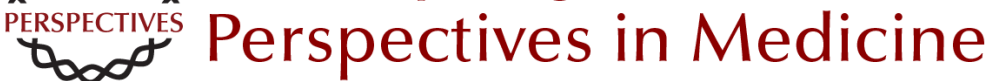

\section{Viral Hepatitis: Past and Future of HBV and HDV}

Emmanuel Thomas, Masato Yoneda and Eugene R. Schiff

Cold Spring Harb Perspect Med 2015; doi: 10.1101/cshperspect.a021345

Subject Collection The Hepatitis B and Delta Viruses

Hepatitis B Virus X and Regulation of Viral Gene Expression

Betty L. Slagle and Michael J. Bouchard

The Woodchuck, a Nonprimate Model for Immunopathogenesis and Therapeutic Immunomodulation in Chronic Hepatitis B Virus Infection

Michael Roggendorf, Anna D. Kosinska, Jia Liu, et al.

Mouse Models of Hepatitis B Virus Pathogenesis Matteo lannacone and Luca G. Guidotti

Therapy of Delta Hepatitis

Cihan Yurdaydin and Ramazan Idilman

Immune Response in Hepatitis B Virus Infection Anthony Tan, Sarene Koh and Antonio Bertoletti

Hepatitis D Virus: Introduction and Epidemiology Mario Rizzetto

Management of Chronic Hepatitis B in Patients from Special Populations

Ching-Lung Lai and Man-Fung Yuen

Hepatitis B Virus Genotypes and Variants

Chih-Lin Lin and Jia-Horng Kao
Origins and Evolution of Hepatitis B Virus and Hepatitis D Virus

Margaret Littlejohn, Stephen Locarnini and Lilly Yuen

Assembly and Release of Hepatitis B Virus Lisa Selzer and Adam Zlotnick

Hepatitis D Virus Replication John M. Taylor

Treatment of Liver Cancer

Chun-Yu Liu, Kuen-Feng Chen and Pei-Jer Chen

Hepatitis B Virus and Hepatitis D Virus Entry, Species Specificity, and Tissue Tropism Koichi Watashi and Takaji Wakita

Hepadnavirus Genome Replication and

Persistence Jianming Hu and Christoph Seeger

The Chimpanzee Model for Hepatitis B Virus Infection Stefan F. Wieland

Hepatitis B Virus Epidemiology Jennifer H. MacLachlan and Benjamin C. Cowie

For additional articles in this collection, see http://perspectivesinmedicine.cshlp.org/cgi/collection/ 